\section{Estudo \\ CoDebate}

em Testão

Plamejamento
Revista Estudo \& Debate, Lajeado, v. 24, n. 3, 2017. ISSN 1983-036X

DOI: http://dx.doi.org/10.22410/issn.1983-036X.v24i3a2017.1374

\title{
PLANTAS MEDICINAIS: EDUCAÇÃO AMBIENTAL E SABER POPULAR NAS ESCOLAS FUNDAMENTAIS DE ARACAJU/SE
}

\author{
Carlos Alberto Vasconcelos ${ }^{1}$, Maria Salete Barreto ${ }^{2}$
}

\begin{abstract}
Resumo: $\mathrm{O}$ uso das plantas medicinais pela população, em especial a nordestina, é uma transmissão de conhecimentos científico e, principalmente popular bastante presente em nossa cultura. Assim, o ambiente escolar deve ser um locus de reprodução e educação desses saberes. Com esta perspectiva, pretende-se, elucidar o resgate e traçar um panorama da tradiçáo do uso das plantas medicinais pela população do Conjunto Bugio em Aracaju/SE, além de analisar os seus reflexos no cotidiano escolar da comunidade. Foi uma pesquisa qualitativa, com viés no estudo de caso resultante de trabalho monográfico de um Curso de Especialização em Educação Ambiental, a qual nos levou a perceber que há necessidade de programas que valorizem o uso e o cultivo de plantas medicinais na comunidade; que esta prática seja vista como alternativa sustentável, de acesso ao tratamento de doenças e enfermidades, reforçando a importância e o valor dos bens naturais e que a escola, como espaço de discussão, debate e formadora de ideias, contribua para projetos e divulgação de estratégias viáveis e sensibilizadoras de educação ambiental.
\end{abstract}

Palavras-chave: Plantas Medicinais. Saber Popular. Escola.

\section{MEDICINAL PLANTS: ENVIRONMENTAL EDUCATION AND KNOW PEOPLE IN BASIC SCHOOLS ARACAJU / SE}

\begin{abstract}
The use of medicinal plants by the population especially of Northeastern is a transmission of scientific knowledge and especially popular very present in our culture. So the school environment should be a locus of reproduction and education of these knowledge. With this perspective it is intended of elucidate the rescue and draw one perspective of the tradition of the use of medicinal plants by the Bugio set population in Aracaju / SE besides analyzing their reflections in the school routine the community. It was a qualitative research with bias in case study result of the work monograph of a Specialization Course in Environmental Education, which led us to realize that there is a need for programs that value the use and the collective cultivation of medicinal plants in the community and that this practice it should be view as a sustainable alternative of access to treatment of illness and the infirmities reinforcing the importance and the value of natural assets that school as a space of discussion, debate and forming of ideas it should to contributes for projects and dissemination of viable and sensitizing strategies for environmental education.
\end{abstract}

Keywords: Medicinal Plants. Popular knowledge. School

1 Geógrafo e Pedagogo (FUNESO); Dr. em Geografia (UFS); Prof. do Depto de Educação e do Programa de Pós-graduação em Ensino de Ciências e Matemática PPGECIMA/UFS; geopedagogia@yahoo.com.br

2 Bióloga e Especialista em Educação Ambiental (Faculdade Atlântico); msaletebarreto@yahoo.com.br 


\section{Introdução}

Discutir sobre plantas medicinais é atual e importante para a sociedade capitalista periférica. A ciência médica e farmacêutica evoluiu muito nos países desenvolvidos e está à disposição do mundo, notadamente para as famílias e indivíduos que podem pagar tais serviços e medicamentos.

De certo, que determinadas especialidades e alguns medicamentos tornaram-se inacessíveis para o trabalhador médio dos países periféricos, por exemplo, no caso brasileiro, onde a renda média familiar gira em torno de dois salários mínimos, permitindo níveis baixos de reprodução e de saúde do trabalhador e de sua família. Em geral, nessas sociedades, pequena parte da populaçáo tem acesso aos serviços públicos de qualidade para assistência e tratamento com medicamentos prescritos pela medicina formal curativa. O Estado atende precariamente o cidadão e disponibiliza pequeno número de drogas produzidas pela indústria farmacêutica e química a preços acessíveis aos trabalhadores. Por outro lado, há enorme variedade de plantas medicinais de uso popular, difundidas por geraçóes de famílias de trabalhadores com origem rural, portadores deste conhecimento empírico, hoje também reconhecido pela pesquisa acadêmica, sendo difundidos nas cidades o conhecimento e o cultivo.

Diante do contexto explícito, tem-se que a utilização de plantas medicinais pela comunidade apresenta-se como mais um campo de atuação da Educação Ambiental, tendo em vista a preservação das espécies e a reaproximação do ser humano com a natureza, bem como alternativa à cura de doenças, principalmente pela população de baixo poder aquisitivo. As experiências educativas utilizando plantas medicinais nas escolas da rede pública do país vêm sendo testadas com a finalidade de permitir que crianças e jovens desenvolvam noçóes de cooperação, responsabilidade e consciência ambiental.

Com isso, este texto discute a temática Plantas Medicinais como forma de promover a educação ambiental e constructo importante no aprendizado cotidiano em uma comunidade no município de Aracaju/SE. A problemática retratada é a falta de articulação e de valorização do saber cultural com o saber científico, aquele repassado dentro do ensino formal, que desvaloriza o potencial de conhecimento popular e da cultura regional em favor de práticas estrangeiras dominantes e elitistas. É uma espécie de alienação do sistema educacional brasileiro que, adotando tecnologias e ciência global, deixa em segundo plano o conhecimento local fundado no saber popular e mantido pela cultura, que tem efeito mais democrático do que aquele disseminado pelo poder global.

Assim, e tendo em vista os objetivos propostos, é importante (re)conhecer as plantas medicinais utilizadas e suas formas de uso, principalmente, quanto à sua disseminação dentro de uma comunidade; investigar se esse conhecimento chega às escolas e de que forma é trabalhado ou levado em consideração, já que se trata de uma cultura popular de caráter altamente marcado pela resistência, traço cultural de uma comunidade densamente impactada pelas formas modernas e urbanas de viver. 


\section{Trilhando o percurso teórico}

A utilização de plantas para o tratamento da saúde teve seu registro em diferentes épocas na história da humanidade e permanece até os dias de hoje fazendo parte da cultura de diferentes comunidades populacionais. Embora a medicina moderna esteja bem desenvolvida na maior parte do mundo, a Organização Mundial da Saúde (OMS) reconhece que grande parte da população dos países em desenvolvimento depende da medicina tradicional para sua atenção primária, tendo em vista que $80 \%$ desta população utilizam práticas tradicionais nos seus cuidados básicos de saúde e $85 \%$ utilizam plantas ou suas preparaçóes (BRASIL, 2006).

Esta utilização na cura ou alívio de doenças, que para muitos poderia parecer misticismo, feitiçaria ou folclore, torna-se hoje objeto de pesquisas científicas com validade comprovada diante da fitoquímica e da farmacologia. Desta forma, define-se o conceito de plantas medicinais, como toda e qualquer planta que atue de maneira benéfica no combate ou minimização de qualquer malefício no organismo humano (BARLEM, 1995).

As vantagens conseguidas no tratamento com plantas medicinais são inegáveis e a excelente relação custo/benefício, ou seja, ação biológica eficaz com baixa toxicidade e efeitos colaterais devem ser aproveitados, uma vez que a natureza oferece gratuitamente a cura para as doenças sendo esta terapia já reconhecida pela OMS. (LIMA, PIRES, VIEIRA 2014).

Segundo os autores mencionados, considerando a ampla diversidade de espécies vegetais, bem como a riqueza étnico-cultural do Brasil, o uso popular de plantas medicinais é bastante relevante. Por isso, os estudos etnobotânicos são fundamentais, uma vez que possibilitam o resgate e a preservação dos conhecimentos populares das comunidades envolvidas. A vasta gama de informaçóes sobre o uso de centenas de plantas como remédios, em todos os lugares do mundo, leva à necessidade de se desenvolver métodos que facilitem a enorme tarefa de avaliar cientificamente o valor terapêutico de espécies vegetais (ELISABETSKY, 2001).

Desta forma, estudos relacionados com a medicina popular têm merecido cada vez mais atenção, devido à gama de informações e esclarecimentos que fornecem à ciência contemporânea, sendo notável o crescente número de pesquisas na área, como as realizadas por Amoroso; Gély (1988), com o uso de plantas medicinais por caboclos do Baixo Amazonas, em Barcarena no Pará.

As populaçóes locais, em geral, possuem uma proximidade muito grande com o meio à sua volta. Isto ocorre, dentre outros motivos, pela necessidade de explorar do meio, recursos que serão utilizados para as mais variadas finalidades. Algumas características desejáveis das plantas medicinais são: sua eficácia, baixo risco de uso, assim como reprodutibilidade e constância de sua qualidade (TOLEDO et al. 2003).

Nesta perspectiva a Educação Ambiental (EA) como formação e exercício da cidadania, refere-se como uma nova forma de encarar a relação do ser humano com a natureza, baseada numa nova ética, que pressupóe outros valores morais e uma forma diferente de ver o mundo e os seres humanos (JACOBI, 2003) 
Com esta compreensão, é mister salientar que o princípio e o fim de uma educação ambiental com o despertar da consciência ecológica, substanciada por uma razáo crítica percebe as relaçóes de poder de caráter dominador e explorador, que desestruturam, rompem laços, produzem cisão, degradando homem e natureza. Assim como, reciprocamente, deve substanciar-se pela promoção do sentimento de pertencimento solidário, o que interconecta, o que integra unidade e multiplicidade. É uma educação ambiental do "ser amoroso," que assim estabelece seus elos com o mundo, a do "saber cuidar" como uma "ética do humano de compaixão pela terra” (BOFF, 1999, p. 38).

Essa EA visa à sustentabilidade da vida do planeta, estabelecendo-se num movimento que provoca rupturas e religaçóes fundantes de um novo paradigma, que de certa forma retrata a questão da cultura popular, a qual apresenta muitas definições e ambiguidades. Contudo, essa cultura é um tema merecedor de amplo tratado, evidenciando sua complexidade. Então, será adotada para esse estudo, a definiçấo de cultura como uma herança social, relacionada a um legado de informações, conhecimentos, competências, técnicas, símbolos, significados, dentre vários outros elementos que permitem ao homem ver, entender e agir no mundo. Esse legado é histórico e dialético, fruto das inúmeras relações sociais existentes entre os homens e entre homens e a natureza. Desmembrando essa definição, vê-se que a cultura não é fixa no tempo, ela é uma construção definida ao longo da história, por isso seu caráter histórico. Além disso, é uma construção resultante da dialética formativa da identidade humana em determinado contexto histórico, espacial, social, etc.., cujo homem nasce em um mundo dado, já construído, sem a sua participação.

Como diz Schwanitz (2004), ao procurar sobreviver neste mundo, o indivíduo é educado por outros que vieram antes dele e que o introduzem a determinadas regras de sobrevivência. No entanto, esse indivíduo age no mundo, por meio de seu trabalho, transformando-o para que ele possa se adequar a este mundo novo construído.

Desta feita, o propósito da educação ambiental é promover a aproximação do homem com a natureza para que, através de formas sustentáveis de relação, seja possível construir um ambiente ecologicamente mais justo (DIAS, LEAL, JUNIOR, 2016).

Diante dessa premissa, e pensando na prática de uma educação ambiental libertadora, que promova a interação e a possibilidade de outro comportamento, fez-se necessário verificar através de entrevistas com os sujeitos que compóem o ambiente escolar comunitário, se a cultura do uso das plantas medicinais, tão comum na comunidade, é respeitada e valorizada na escola.

De certo, o desenvolvimento adotado pela política local, segundo Caballero, (1983, p. 25-28) pode,

determinar a conservaçấo cultural e ambiental das plantas medicinais, ou levar ao extermínio dos ecossistemas naturais e das formas tradicionais de manejo dos recursos vegetais, que são progressivamente desprezadas por formas modernas, altamente destrutivas e orientadas à produção para o mercado capitalista.

Embora o uso dos recursos vegetais, em especial das plantas medicinais seja um traço da cultura da comunidade do Conjunto Bugio, essa manifestaçáo não ocorre com o 
mesmo significado dentro do ambiente escolar, como também a educação ambiental, casos que demonstram a necessidade de projetos envolvendo práticas de EA, para se chegar a uma consciência ambiental e, consequentemente, à preservação/conservaçáo dos recursos naturais e vegetais, acarretando, através da interdisciplinaridade e/ou dialética do universo, subsídios teóricos que propiciem um desenvolvimento sustentável (VASCONCELOS, 2000).

\section{Percurso Metodológico}

Para trilhar o percurso que originou este texto buscou-se apoio na abordagem qualitativa, bibliográfica com estudo de caso e entrevistas. Para Gil (2010) a pesquisa bibliográfica possibilita o trabalho de consulta à biblioteca nas fases iniciais e pode tornarse intenso, justamente, nas consultas que se processam na coleta de dados em busca de material publicado como livros, periódicos, jornais, revistas, e que ocorre durante todo o processo de pesquisa e estudo.

A abordagem qualitativa por responder a questóes particulares, busca um nível de realidade que provém de significados, motivos, aspiraçóes, valores e atitudes que não podem ser quantificados (MINAYO, 2002). Este tipo de abordagem difere do método quantitativo, pois "aprofunda-se nos significados das açôes e relaçóes humanas, um lado não perceptível e não captável em equações, médias e estatísticas" (p. 22). Sua preocupação está mais para o processo e náo para o produto.

Tendo em vista ser uma abordagem metodológica de investigação, optou-se pela escolha do estudo de caso que segundo Yin (2004), trata da investigação empírica de um fenômeno contemporâneo em seu contexto. Além de entrevistas semiestruturadas com roteiros elaborados de acordo com o tema proposto onde os participantes puderam discorrer sobre suas experiências de forma espontânea.

Estas foram gravadas e depois transcritas pelos investigadores, abordando questôes ligadas ao uso, às propriedades e às estratégias de perpetuação das plantas medicinais na vida dos moradores. Para Minayo (2002, p. 57), através da entrevista, "o pesquisador busca obter informes contidos nas falas dos atores sociais".

Ressalta-se ainda que o trabalho foi sistematicamente registrado com fotografias autorizadas que serviram como fonte náo apenas de ilustraçáo, mas para relacionar o escrito à realidade vivida.

Com essa perspectiva, pretende-se elucidar o resgate e traçar um panorama da tradição do uso das plantas medicinais junto à população do Conjunto Bugio em Aracaju/ SE, e para analisar seus reflexos no cotidiano escolar dessa comunidade, escolheu-se como locus do estudo, o Colégio Estadual Secretário Francisco Rosa Santos, que comporta cerca de 900 alunos e oferece o Ensino Fundamental e Médio à população estudantil do bairro e das adjacências.

Para efetivação decidiu-se por amostra significativa e aleatória com 150 moradores do bairro, 10 professores, dos 38 que compóem o ensino fundamental da referida escola e 20 alunos do $6^{\circ}$ ao $9^{\circ}$ ano, além da diretora e as coordenadoras. A execução pesquisa supracitada deu-se num período de 20 dias entre os meses de agosto e setembro do ano 
de 2013. Foram feitas concomitantemente as visitas em residências, onde se entrevistou um morador por domicílio, e na escola os alunos, professores e gestores, de acordo com a disponibilidade de cada um.

Dentre os teóricos utilizados para embasamento optou-se por Araújo (2006), Boff (1999), Braga (2005), Dias, Leal, Junior, (2016), Schwanitz (2004) entre outros que discutem a Educação Ambiental, Plantas Medicinais e Cultura Popular.

\subsection{Contextualizando a área de estudo}

Para maior entendimento far-se-á breve contextualização da comunidade foco de estudo, onde a escola está localizada na qual foram investigadas as residências, bem como sucinto panorama destacando política habitacional e agravos ambientais.

O Conjunto Bugio (Assis Chateaubriand) fica situado na zona norte da cidade de Aracaju, localizado às margens do rio Sergipe. Foi o primeiro megaconjunto construído na época pela Companhia de Habitação, em Sergipe (COHAB). Possuía um total de 2133 casas, num aglomerado de mais de 10.000 moradores. Apesar de ter sido construído na periferia, cresceu em larga escala e passou a ser um bairro, hoje repleto de invasōes e loteamentos, cuja demanda de residências ultrapassou o número de construção no período de 1975 a 1979.

Nessa época, Aracaju estava crescendo em contingente populacional, e a política habitacional privilegiava a construção de conjuntos habitacionais como esse. No entanto, as construçóes desses complexos habitacionais causaram impactos ambientais, com a perda da vegetação nativa e diversas espécies de arbustos frutíferos, sem contar também com a biodiversidade de animais, inclusive os primatas da espécie bugio, que deu nome ao bairro e que atualmente está em processo de extinção (ARAÚJO, 2006).

A partir deste contexto, é mister enfatizar que na década de 1960 o mundo começava a mostrar as consequências do modelo de desenvolvimento econômico, adotado, principalmente, pelos países ricos, traduzido em níveis crescentes de poluição atmosférica; em rios envenenados por despejos industriais; em perda da cobertura vegetal da terra e outros. Os recursos hídricos, por exemplo, sustentáculo e derrocada de muitas civilizaçóes, estavam sendo comprometidos em grande velocidade na história humana.

O Brasil vivia o regime ditatorial, na "Contramão" da tendência internacional de preocupação com o ambiente; mostrava ao mundo o Projeto Carajás e a Usina Hidroelétrica de Tucuruí, iniciativas de alto potencial de degradação ambiental. Nessa conjuntura adversa, criava-se a Associação Gaúcha de Proteçâo ao Ambiente Natural - GAPAM, precursora de movimentos ambientalistas em nosso país, quando ainda não tínhamos nem mesmo uma legislaçáo ambiental, como a maioria das naçóes (SANTOS, 1999).

As consequências desses empreendimentos e os resultados se faráo sentir nos anos posteriores. Cubatão, no Brasil, é um "Exemplo Clássico", onde ocorreu uma explosão ocasionada pelo rompimento de um duto gerando vazamento de 700 mil litros de gasolina entre as moradias, causando um incêndio que vitimou dezenas de pessoas; o acidente de Bophal, na Índia, ocorrido numa indústria química multinacional que operava sem medidas de segurança exigidas em seu país de origem, provocou a morte de milhares de pessoas. Esse 
acidente e o da usina nuclear de Chernobyl são considerados os maiores acidentes ecológicos do século XX. Recentemente no Brasil, pode-se citar o desastre ambiental de Mariana em Minas Gerais que devido ao rompimento de uma barragem provocou uma enxurrada de lama que devastou o distrito de Bento Rodrigues, deixando um rastro de destruição à medida que avança pelo Rio Doce, causando danos irreversíveis ao meio ambiente com os rejeitos de mineração, que eram formados, principalmente, por óxido de ferro, água e lama.

Em todo o mundo, emerge movimentos de lutas, reivindicaçóes para resolução destas e outras questôes que afetavam a população mundial, e em particular as relacionadas ao meio ambiente. Com este enfoque, acontece a conferência de Estocolmo, tendo como uma das suas finalidades tentar conduzir açôes voltadas para educar o cidadão para a solução dos problemas ambientais, salientando-se que foi nesse evento que surgiu o termo "Educação Ambiental".

A Organização das Naçóes Unidas (ONU) foi o organismo responsável pela divulgação e realização dessa nova perspectiva educativa, realizando seminários regionais em todos os continentes, procurando estabelecer os seus fundamentos filosóficos e pedagógicos junto à UNESCO.

Para alguns especialistas falar em educação ambiental, era inútil, contribuir para a formação do indivíduo e para a cidadania, enquanto vários países continuavam fabricando armas nucleares impedindo a participação dos cidadãos nas decisôes políticas.

Decorrente de tal trajetória, nasce outro conceito: "desenvolvimento sustentável" que diz respeito a uma forma de crescimento econômico das naçóes que considerem o comprometimento dos recursos naturais para as futuras geraçóes. A ideia de desenvolvimento sustentável é de "crescimento econômico com controle ambiental", em todos os países do mundo. A desigualdade é tratada como um desajuste a ser superado pela universalizaçáo do desenvolvimento econômico, porém com sustentabilidade (SANTOS, 2007).

\section{Resultados e Discussóes}

A partir de breve cenário teórico metodológico tendo em vista os objetivos propostos é importante (re)conhecer as plantas medicinais cultivadas e suas formas de uso, principalmente, quanto a sua disseminação dentro da comunidade; investigar se esse conhecimento chega às escolas e que forma é trabalhado ou levado em consideração, já que se trata de uma cultura popular de caráter altamente marcado pela resistência, traço cultural de uma comunidade impactada pelas formas modernas e urbanas de viver (BURKER, 1999).

Assim, esse tópico, pretende discorrer sobre os resultados empíricos desenvolvidos e obtidos em pesquisa mais aprofundada, fruto de trabalho monográfico, abordando e analisando a cultura popular de uso das plantas medicinais em uma comunidade periférica de Aracaju no estado de Sergipe e seus reflexos na prática e no cotidiano escolar como estratégia de Educação Ambiental, correlacionando-os com embasamentos teóricos, levando em consideração a concepção de Medina (1994) que tem a EA como um processo constante de aprimoramento de condição humana de vida no mundo. Portanto será mais valorizada 
quanto maior clareza se tenha sobre seu significado e sobre a influência que exerça nas escolhas e decisóes com que se defronta o homem a cada dia

Então, a partir dos dados levantados através do trabalho de campo foi possível identificar que o uso de plantas medicinais na comunidade investigada é uma prática cultural que se desenvolve ao longo dos tempos, motivada pelos resultados e também pela disseminação de informações entre os moradores do núcleo habitacional, os quais, através de seus hábitos e costumes, repassam esse saber para as geraçôes futuras.

Dos 150 domicílios visitados aleatoriamente, e divididos de forma proporcional entre as etapas que compóem o conjunto de casas, pertencentes ao complexo habitacional, observou-se que $80 \%$ dos domicílios possuíam canteiros de plantas medicinais, ou seja, 120 residências. Estes dados podem ser retratados no gráfico a seguir.

Gráfico 01. Quantitativo de residências com canteiro de plantas medicinais.

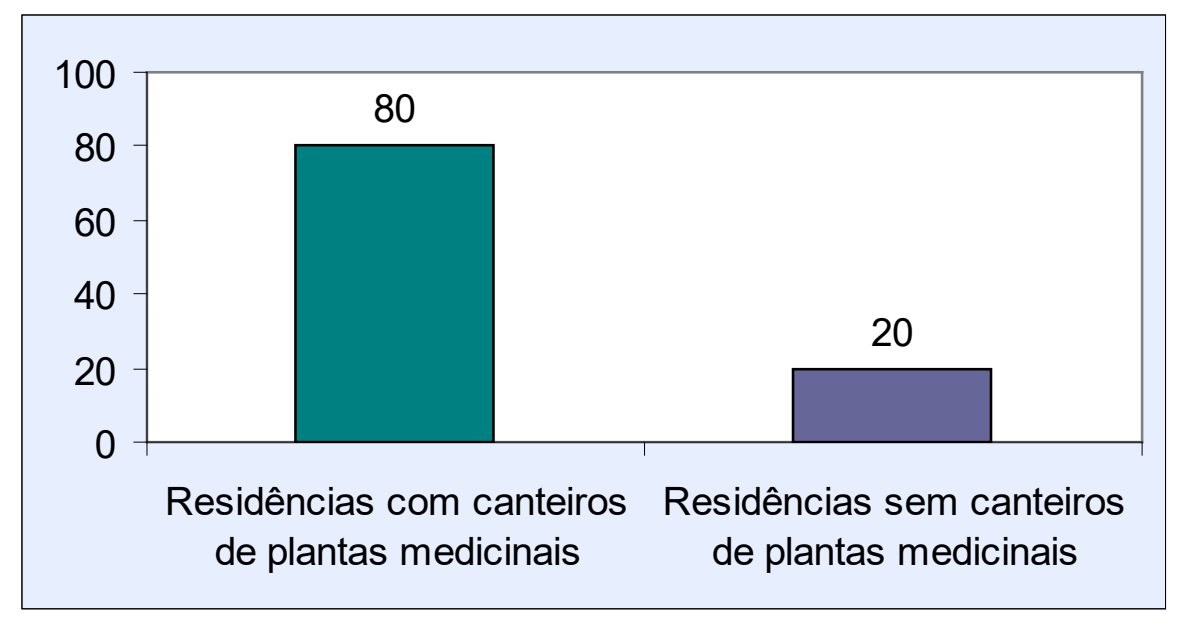

Fonte: Dados da Pesquisa (2013).

Dentro desse percentual de entrevistados, que assume ter canteiros de plantas medicinais em suas residências, afirma fazer uso dessas plantas para tratamento de doenças ou enfermidades.

Sobre essa temática Nogueira (1983), tem examinado seriamente algumas práticas na medicina tradicional com o objetivo de que sejam realizados estudos não só para analisar a sua eficácia, mas também incorporá-las à medicina moderna, aquelas comprovadamente eficazes. Diz ainda o autor que o Ministério da Saúde (MS) quer que a população brasileira volte a tomar remédios extraídos da flora medicinal, incentivando desta maneira as pesquisas que visam conhecer a eficácia de plantas utilizadas na medicina popular e o cultivo destas.

Sugere também que a terapêutica alternativa deverá ser estudada por profissionais diretamente ligados à população, como o enfermeiro, seja em hospitais, em centros de saúde ou junto à comunidade, o que pode ensejar-lhe uma grande oportunidade em educar e esclarecer a população acerca das práticas alternativas benéficas ou nocivas à sua saúde. 
Salienta-se que trabalhos, como o mencionado e este que deu origem a este texto, são bastante relevantes perante as informaçóes e as formas de usos das propriedades medicinais das plantas sedimentadas nas experiências da comunidade, e que mesmo os moradores que não possuem canteiros com plantas medicinais, reconhecem a valor de sua utilização.

Quando perguntado o motivo por optarem pelo uso das plantas como alternativa de tratamento, $40 \%$ apontam que o uso das plantas é mais saudável para o organismo, em detrimento das drogas convencionais vendidas nas farmácias, $30 \%$ dos entrevistados, usam as plantas em decorrência de ser uma alternativa econômica que a compra tradicional de remédios em farmácias, $20 \%$ apontam fazer uso por tradição, movido pela crença dos mais velhos e $10 \%$ apresentaram outros motivos para seu uso, como se pode observar no gráfico a seguir.

Gráfico 02 - Motivos para o uso das plantas medicinais pela população que possui em suas residências

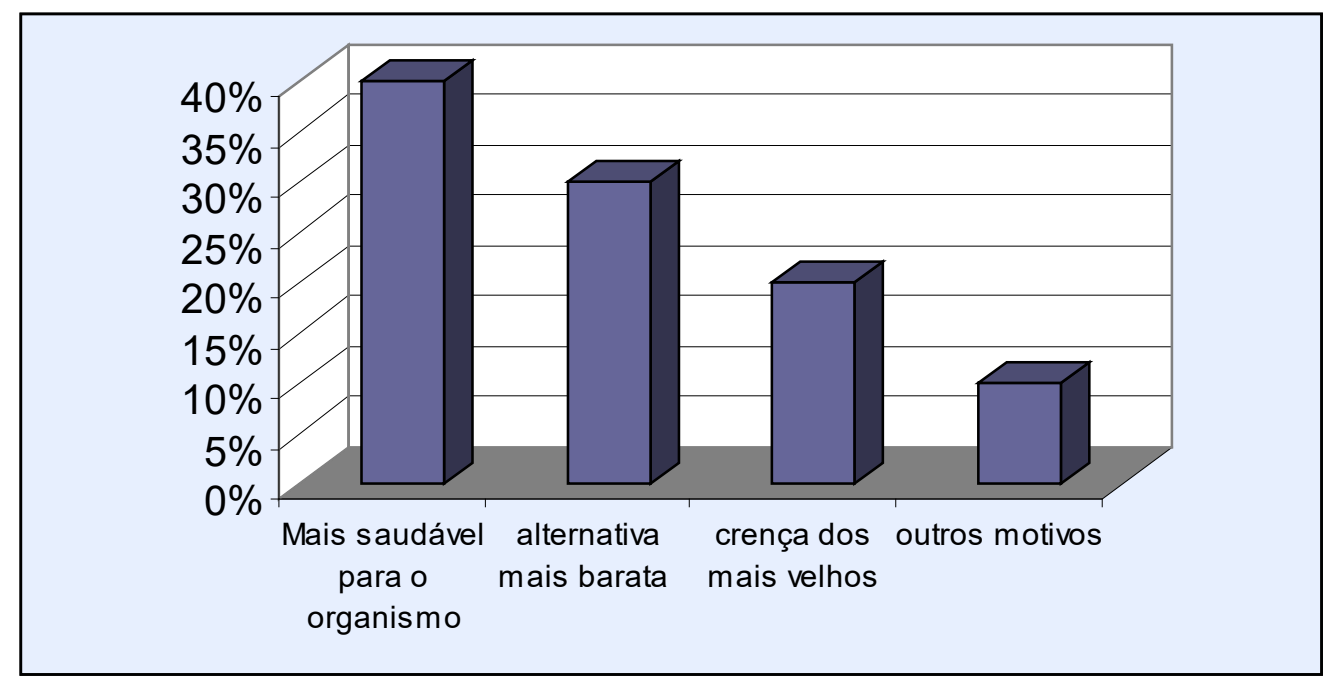

Fonte: Dados da Pesquisa (2013).

O resultado desse levantamento permite evidenciar que o motivo do uso das plantas medicinais na comunidade se dá principalmente por três questôes descritas: por entender que as plantas funcionam como terapia mais saudável ou de menor impacto no organismo; pela condição econômica das pessoas que as utilizam e, por demonstrar a perpetuação de conhecimentos, crenças e tradiçôes do povo, marcadas pela disseminação de informaçóes e fortalecimentos de laços de cultura. Salienta-se também que o uso das plantas é visto pelos moradores como alternativa de tratamento de doenças ou sintomas comuns e de fácil diagnóstico, como gripe, dor de barriga, má digestão, inflamaçôes, cólica, machucados e outras enfermidades.

Quanto à disseminação do conhecimento sobre as propriedades e as formas de uso dessas plantas repassadas para as geraçóes futuras, os entrevistados alegaram que seria para 
o próprio uso e que há incentivos e sabedoria por parte dos mais velhos para utilizaçáo e indicação de chás, tendo em vista ser uma alternativa prática.

Verificou-se também que as formas de cultivo dessas plantas medicinais ocorrem em virtude das construçôes, em geral, de casas com área para ampliação. Devido a esta característica a planta é cultivada diretamente no solo, seja com a construção de canteiros separados por estruturas de pedra ou cimento, seja em solo aberto no fundo do quintal.

Outra alternativa encontrada para manutenção da cultura entre os moradores foi o plantio em vasos, vasilhames ou estruturas fechadas de cimento onde as plantas são cultivadas individualmente, diferente dos canteiros abertos no solo, como podemos verificar na figura a seguir.

Figura 01: Canteiro de plantas medicinais cultivadas em vasos no conjunto Bugio

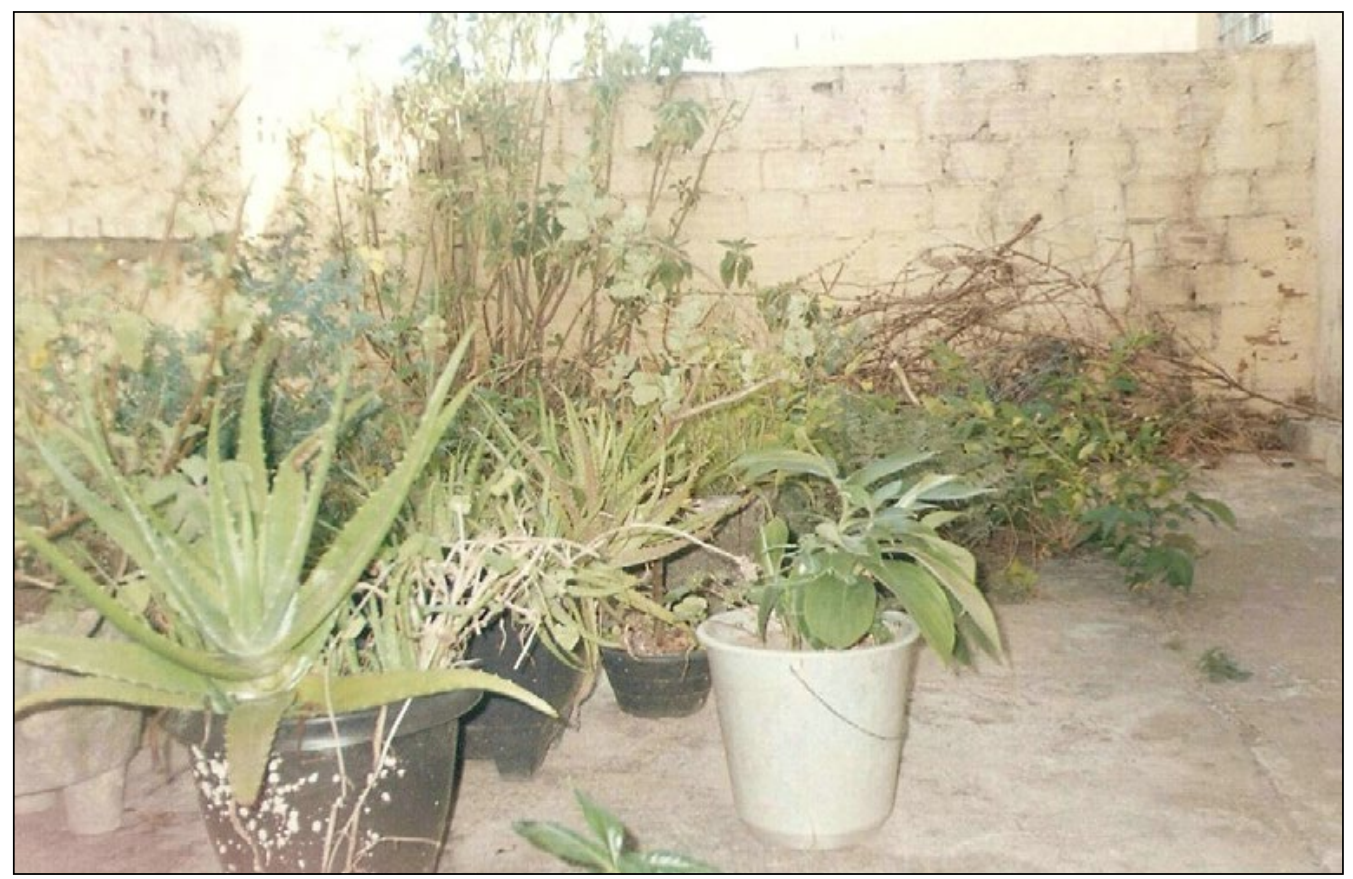

Fonte: Foto dos Autores (2013).

Face ao estudo, constatou-se durante as entrevistas que há uma variação de espécies, possível de ser identificada quanto às categorias de plantas de uso geral e outras, que pela sua especificidade, ficam restritas a poucas residências que possuem canteiros mais antigos.

$\mathrm{Na}$ tabela seguinte, identificam-se os principais tipos de plantas medicinais encontrados com suas recomendaçôes de uso. Convém notar que essas foram as espécies mais citadas dentro do universo das residências que possuem canteiros com plantas medicinais e que foram detectadas durante a pesquisa. Dentre estas, destaca-se por suas variedades e utilidades, o sambacaitá, espécie Hyptis pectinata, popularmente conhecido como canudinho pela comunidade em foco, pertencente à família Lamiaceae. É uma planta utilizada principalmente nos Estados de Sergipe, Alagoas e Ceará na medicina popular para 
o tratamento de inflamações, infecção bacteriana e dores. Ressalta-se que essa planta se propaga facilmente através de sementes (BRAGA, 2005).

Tabela 01 - Principais espécies de plantas medicinais encontradas no conjunto Bugio, número de ocorrência e indicação de usos

\begin{tabular}{c|c|c|c}
\hline NOME POPULAR & NOME CIENTÍFICO & $\begin{array}{c}\text { No DE CITAÇÓES } \\
\text { DE USO }\end{array}$ & INDICAÇÁO \\
\hline Melissa (Cidreira) & Melissa officinales & 42 & Calmante \\
\hline Capim-Santo & $\begin{array}{c}\text { Cymbopogon citratus (De.) } \\
\text { Stapf }\end{array}$ & 33 & Dor de barriga \\
\hline Sambacaitá & Hyptis pectinata & 31 & Inflamaçóes \\
\hline Hortelã & Mentha & 28 & $\begin{array}{c}\text { Dor de estômago e } \\
\text { expectorante }\end{array}$ \\
\hline Babosa & Aloe vera & 22 & Antiqueda capilar \\
\hline Mastruço & Chenopodium ambrosioides & 19 & $\begin{array}{c}\text { Expectorante, vermes e } \\
\text { pancadas }\end{array}$ \\
\hline Boldo & $\begin{array}{c}\text { Plectranthus barbatus } \\
\text { Benth }\end{array}$ & 16 & $\begin{array}{c}\text { Gastrintestinais e } \\
\text { hepáticos }\end{array}$ \\
\hline Pitanga & Eugenia uniflora Berg & 15 & Gripe \\
\hline
\end{tabular}

Fonte: Levantamento de dados (2013). Elaboração: Salete Barreto.

A ocorrência e o cultivo das plantas medicinais mais comuns na área analisada não diferem das informaçóes coletadas no meio científico, lembrando que a cultura popular amplia essa aplicação, refazendo um ciclo constante de pesquisa e comprovação.

Assim, a utilização de plantas na medicina popular é uma prática antiga, vinda desde o início das grandes civilizações, apesar das descobertas e evolução da indústria farmacêutica (SAAD et al., 2009). O costume de se utilizar plantas como medicamento se perpetua em muitas sociedades tradicionais, pois possuem uma vasta farmacopeia natural. Muitos desses vegetais são encontrados em seu hábitat natural e passam a perder seu espaço com o aumento da população; outros são cultivados em ambientes modificados, como acontece na comunidade pesquisada.

É mister salientar que ao longo dos anos muitas pesquisas foram realizadas com a finalidade de esclarecer e comprovar a eficácia no uso das plantas medicinais. Diversas destas são feitas em mercados e feiras livres e revelam a necessidade de conhecimento na área de etnobotânica e farmacognosia ${ }^{3}$, pois o conhecimento empírico tem sido transmitido de geração a geração e muitas vezes são contraditórios, provocando o desencontro do conhecimento científico. Contudo, não convém desprezar toda uma sabedoria popular.

Outrossim, comprovou-se na parte prática do trabalho, que há ausência de canteiros de plantas medicinais no ambiente escolar, bem como projetos que envolvam a EA e hortas, dificultando assim o uso dessas plantas, mas a própria escola reconhece não trabalhar

3 A farmacognosia é um dos mais antigos ramos da farmacologia. Ela é praticada por farmacêuticos, e tem como alvo os princípios ativos naturais, sejam animais ou vegetais. 
a questão com seus alunos, com exceção de uma professora de Ciências, que aborda a importância das plantas medicinais durante o desenvolvimento da Feira de Ciências, que ocorre uma vez por ano, contudo a prática e valorizaçáo desse traço cultural permanecem pouco trabalhadas, porque não se faz entre os alunos, mesmo para tratar sintomas simples, o uso de chás na escola, porém entre os professores e a direção foi possível constatar o uso de plantas trazidas de casa em forma de chá.

Percebe-se que a principal questão aqui trabalhada é a negação dessa cultura no ambiente escolar, o que acarreta uma perda de valor, pois a escola deve promover a valorização da relação comunitária com o uso de plantas medicinais, como possibilidade de construção de uma alternativa de projeto de EA, até agora inexistente.

Percebeu-se com as entrevistas que a escola ainda é tímida para lidar com questóes ligadas à cultura popular, pois esse (re)conhecimento é contraditório, diante de um ambiente que tem compromisso com a cientificidade. Tal fato pode ser comprovado com o depoimento da diretora da escola em 10 de setembro de 2013, quando diz: "Náo temos canteiro de plantas na escola, já teve no passado, hoje não temos mais".

Nas entrevistas com os professores ficou nítido que, embora a maioria $84 \%$ tenha canteiro de plantas medicinais em suas residências, eles sentem-se pouco à vontade para fazer uso com seus alunos, apesar de admitir que se essa fosse uma prática da escola, seria benéfico para os alunos.

Entre os alunos prevalecem os reflexos do cotidiano da comunidade, pois as entrevistas comprovaram que a maioria faz uso das plantas medicinais em suas casas, mas, em menor quantidade que os professores, o que demonstra um desconhecimento acerca dos benefícios econômicos e da saúde. Por sua vez, o Ministério da Saúde (MS) tem encorajado o desenvolvimento de estudos com plantas tradicionais, com a esperança de obter os possíveis benefícios que as pesquisas sobre esse assunto podem trazer; e objetiva evitar efeitos irracionais ou prejuízos que esse tipo de medicina pode ocasionar. Todavia, não adentraremos nesta seara, devido à polêmica que ainda se estabelece entre o conhecimento científico e a sabedoria ou conhecimento popular.

Entretanto, levar em consideração a educação ambiental é imprescindível para o avanço de açóes pertinentes a conscientização e preservação de recursos vegetais, dentre estes o cultivo e utilização de plantas medicinais.

De acordo com Medina (2000 p 117):

A compreensão da complexidade da questão ambiental exige uma abordagem metodológica
que, sem abrir mão do saber cientifico especializado, supere a fragmentação dos diferentes
compartimentos disciplinares em que estão divididas as diversas áreas do conhecimento.
É necessário se utilizar da contribuiçáo das várias disciplinas (conteúdo e método) e das
várias representaçôes sociais dos agentes envolvidos, para se construir uma base comum de
compreensão e atuação sobre o problema ou potencialidade ambiental identificada.

Para tanto, os pesquisadores envolvidos com o processo, necessariamente devem considerar a importância dos conhecimentos das populaçóes envolvidas, tendo em vista a 
especificidade do contexto cultural e natural em que são produzidos e as formas de relações entre a sociedade e a natureza que eles manifestam.

No gráfico a seguir comprova-se a utilização das plantas por parcela dos sujeitos investigados.

Gráfico 03: Porcentagem de alunos que fazem uso de plantas medicinais

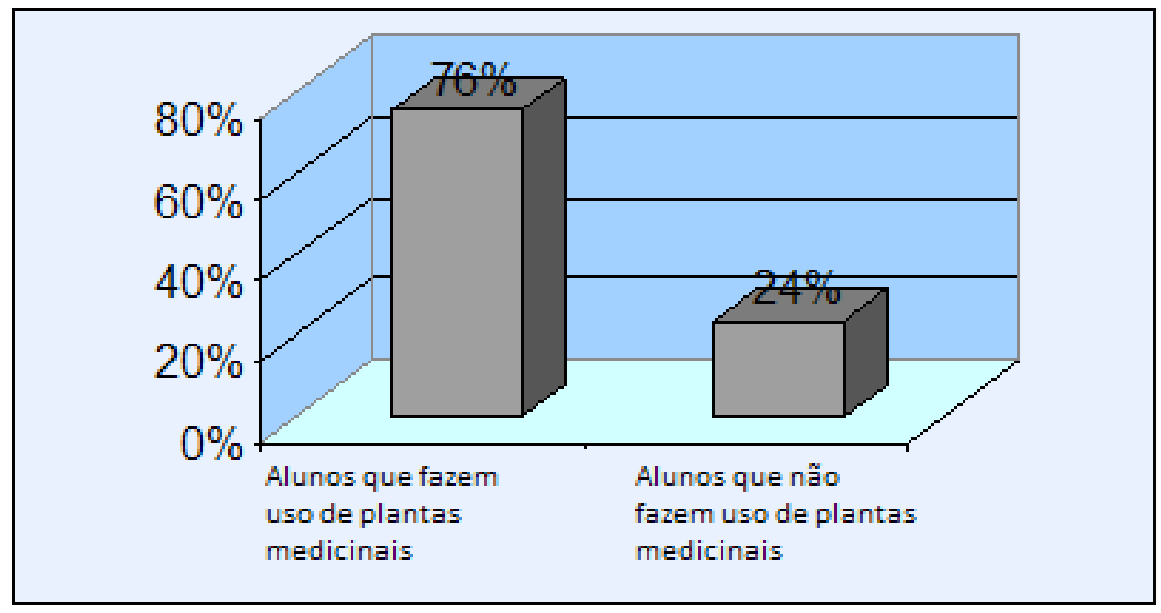

Fonte: Dados da pesquisa (2013).

Ao que indica então, a tradição e a força do uso de plantas medicinais na comunidade encontram na escola um ambiente de resistência, cabendo, portanto, um outro comportamento, já que essa manifestação parece bastante legítima entre os alunos e os seus pais respectivos.

Além disso, esse traço cultural poderia ser devidamente aproveitado como alternativa e estratégia de fortalecimento dos laços comunitários, funcionando como excelente elemento gerador de projetos de Educação Ambiental dentro da escola. Todavia, como averiguado, essa oportunidade não é devidamente aproveitada, causando um distanciamento entre a realidade local e a escola.

\section{Consideraçóes finais}

É certo que a cultura popular sempre esteve presente nos programas e conteúdos escolares. De um jeito formal ou de forma transversal, sempre há um espaço na educação para se tratar desse assunto. A relaçáo educaçáo e cultura pode proporcionar respostas às preocupaçóes cotidianas do educador, pois os relatos revelaram uma discrepância no entendimento de possibilidades da ação da escola sobre a cultura e a vida da sociedade.

No entanto, os participantes da pesquisa demonstraram uma percepção ampliada da dimensão da escola dentro da sociedade, atribuindo-lhe um papel transformador bastante idealizado. A ideia de uma escola que tenha a capacidade de desconstruir e reconstruir o mundo humano, de modificar costumes, padróes de comportamento da sociedade, transformar vidas, dentre outros objetivos semelhantes e necessários, nem sempre se 
confirma na prática cotidiana das escolas, com repercussão sobre a sociedade e, de modo mais específico, na perpetuação do cultivo e utilização das plantas medicinais.

Em um país como o Brasil com tamanha diversidade biológica, de extensão territorial, com tantas expressóes diferentes, com tantos jeitos de ser, de brincar, de conviver e rezar, que vão se modificando de lugar para lugar, e a toda hora, náo podemos falar de uma única cultura, mas das muitas culturas que o formam; e estas, na maioria das vezes, estấo associadas à natureza.

Diante de tudo que discorremos, será ainda possível falar de educação sem integrá-la à questão cultural e ambiental? Certamente não. E a resposta é não, porque a educação é resultado das práticas culturais dos grupos sociais. O próprio processo de ensinar e aprender revela essas práticas.

Então, levando-se em consideração as características e a crise sociopolítica vivida pelo mundo, marcada principalmente pelos contrastes e diferenças provocados pela crise ambiental, ou seja, pela falência do modo de exploração capitalista da natureza, em que o mundo passou a valorizar as sociedades e o modo de vida urbano, distanciando-se das formas de convívio com a natureza e seus recursos como parte dele, separando antagonicamente essas partes, as culturas populares, como o uso das plantas medicinais entre as comunidades, como no caso do estudo, do Conjunto Bugio (Aracaju/SE), pode-se indicar que as formas de resistências reproduzidas oportunizam possibilidades de projetos de educação ambiental, que a escola enquanto locus formal de resistência e saber, deveria aproveitar com mais competência.

Além disso, devemos perceber também que tais formas de manifestação são resultados da formação social dos moradores da comunidade analisada, os quais, na sua maioria, advém de localidades fora do eixo urbano da capital, ou porque a geração de pais e avós que compóem o perfil populacional da comunidade é originária do interior do estado, onde as formas e as tradiçôes ligadas ao uso de plantas medicinais são mais intensas.

Seria, pois, necessário, no nosso ponto de vista, um programa de valorizaçáo do uso e cultivo de plantas medicinais na comunidade para que estas fossem vistas como uma alternativa sustentável de acesso ao tratamento de doenças e enfermidades, reforçando a importância e o valor dos bens naturais. Ea escola pública poderia ser esse cenário de discussão, debate e formadora de ideários, traçando, assim, estratégias viáveis e sensibilizadoras de educação ambiental na comunidade.

\section{Referências}

AMOROSO, M.C.M.; GÉLY, A.L. Uso de plantas medicinais por caboclos do baixo Amazonas, Barcarena, PA, Brasil. Boletim do Museu Paraense Emílio Goeldi, v.1, p.47131, 1988.

ARAUJO, H. M. de. O ambiente urbano: visões geográficas de Aracaju. São Cristóvão: Editora UFS, 2006. 
BARLEM, S.M.S. Contribuiçáo ao conhecimento fitoterápico da comunidade de Itacoara, município de Benevides, Estado do Pará. 1995. Trabalho de conclusão de curso (Ciências Biológicas) - Centro de Ensino Superior do Pará, Belém, PA, 1995.

BOFF, L. Saber cuidar: ética do humano - compaixão pela terra. 9. ed. Petrópolis: Vozes, 1999.

BRAGA, R. Plantas do nordeste, especialmente do Ceará. Fortaleza; Editora da UFCE, 2005.

BRASIL. Política nacional de plantas medicinais e fitoterápicos. Ministério da Saúde/ Secretaria de Ciência, Tecnologia e Insumos Estratégicos, Departamento de Assistência Farmacêutica. Brasília: Ministério da Saúde, 2006.

BURKE, P. Cultura popular na idade moderna. São Paulo: Companhia das Letras, 1989.

CABALLERO, J. Perspectiva para el quehacer etnobotânico em México. In: BARRERA, A. (Ed.). La etnobotânica: três puntos de vista e una perspectiva. Xalapa: Instituto Nacional de Investigaciones sobre Recursos Bióticos. p. 25-28, 1983.

DIAS, S. L; LEAL. A. S; JUNIOR, S. C. (Orgs.) Educação ambiental: conceitos, metodologia e práticas. Tupã/SP: ANAP, 2016.

ELISABETSKY, E. Etnofarmacologia como ferramenta na busca de substâncias ativas. In: SIMÓES C.M.O; SCHENKEL, E.P.; GOSMAN G; MELLO, J.C.P.; MENTZ L.A.; PETROVICK, P.R. (Eds). Farmacognosia: da planta ao medicamento. 3.ed. Porto Alegre: UFSC. p. 91-104, 2001.

GIL, A. C. Como elaborar projetos de pesquisa. ed., 5. São Paulo, Atlas, 2010

JACOBI, P. Educação ambiental, cidadania e sustentabilidade. Caderno de Pesquisa, v.2, n.118, 189-216, 2003.

LIMA, R. L; PIRES, L. S. S; VIEIRA, N. G. A educação ambiental e o uso de plantas medicinais utilizadas pela população do distrito de União Bandeirante-Rondônia. REGET, v. 18 n. 4 Dez 2014, p.1351-1360

MEDINA, N. M. Elementos para a introdução da dimensão ambiental na educação escolar - 1. ${ }^{\circ}$ Grau. In: BRASIL. Ministério do Ambiente e da Amazônia Legal. Instituto Brasileiro do Meio Ambiente e dos Recursos Naturais Renováveis. Amazônia: uma proposta interdisciplinar de educação ambiental. Brasília: IBAMA, 1994 (Documentos Metodológicos).

MINAYO, M. C. de S. (Org.). Pesquisa social: teoria, método e criatividade. 21a ed. Petrópolis: Vozes, 2002. 
NOGUEIRA, M. J. C. Fitoterapia: a volta à natureza. Enfoque, São Paulo, v. 12, n. 1, p. 8-11, ago. 1984 .

SAAD, G. A et al. Fitoterapia contemporânea: tradição e ciência na prática clínica. Rio de Janeiro: Elsevier, 2009.

SANTOS, M. J. S. Mata do Junco (Capela/SE): identidade territorial e gestão de conflitos ambientais. 2007. Dissertação (Mestrado em Desenvolvimento e Meio Ambiente) - Programa de Pós-Graduação em Desenvolvimento e Meio Ambiente, Universidade Federal de Sergipe. São Cristóvão, SE, 2007.

SANTOS, M. M. O sertáo sergipano do Sáo Francisco e os movimentos sociais no campo. 1999. Dissertação (Mestrado em Geografia) - Núcleo de Pós-Graduação em Geografia, Universidade Federal de Sergipe, São Cristóvão, SE, 1999.

SCHWANITZ, Dietrich. Cultura: tudo o que é preciso saber. Lisboa: Dom Quixote, 2004.

TOLEDO, A.C.O.; HIRATA, L. L.; CRUZ, M.; BUFFON, M.; MIGUEL, M.D.;

MIGUEL, O.G. Fitoterápicos: uma abordagem farmacotécnica. Revista Lecta, v.21, n.2, p.7-13, 2003.

VASCONCELOS, C. A. Meio ambiente e espacialização da citricultura no município de Sairé-PE. 2000. Dissertação (Mestrado em Geografia) - Núcleo de Pós-Graduação em Geografia, Universidade Federal de Sergipe. São Cristóvão, SE, 2000.

YIN, Robert K. Estudo de caso: planejamento e métodos. 2a ed., Porto Alegre: Bookman, 2004. 